\title{
Innateness of the adrenalectomized rat's acceptance of salt
}

\author{
Robert C. Bolles, Steven I. Sulzbacher ${ }^{1}$ and Harriet Arant \\ HOLLINS COLLEGE
}

\begin{abstract}
The latency to eat food in a novel situation was measured in adrenalectomized and normal control rats. Ss were offered either salty or plain food. The results indicate that adrenalectomized rats show a high acceptance of salty food at their first encounter with it.
\end{abstract}

\section{Problem}

It is well known that many animals, including the rat, do not survive bilateral adrenalectomy for more than a week or so unless they are given hormones or a high concentration of dietary $\mathrm{NaCl}$. It is also well known that adrenalectomized animals will accept and may even prefer salt concentrations in their food and drinking water that are not accepted by normal animals. It is not yet certain, however, if this remarkable adaptation occurs because animals learn that salt is beneficial or if it is some immediate, innate adjustment produced by the adrenal insufficiency.

Richter (1939) tested rats with a series of gradually increasing salt concentrations starting with sub-threshold values, and found that a preference for saline solutions developed before enough salt had been consumed to appreciably affect the salt deficit. Richter argued that the possibility of learning had been ruled out with this procedure and concluded that the preference represented a mopification of the taste receptors. Carr (1952) and others have shown, however, that the sensory threshold for salt is not changed by adrenalectomy, and Smith, Pool and Weinberg (1958) have shown that there are learning effects in the salt preference, again in a situation in which little or no salt was consumed. Furthermore, Richter's preference results were based upon consumption data obtained over 24-hr. periods, so whereas his animals may not have received sufficient salt in the tests to affect their need state, they received ample opportunity in terms of time or consummatory behavior for learning to occur. Stellar (1955) found a strong preference for high $\mathrm{NaCl}$ concentrations during the first hour of testing in adrenalectomized rats but, because of the rapid absorption of $\mathrm{NaCl}$, it is possible that learning occurs even during a $1-\mathrm{hr}$, test.

\footnotetext{
1 Now at Emory University.
}

Thus the question of the immediacy of the preference remains open. In the present study rats were permitted only a brief contact with salty food and the latency, persistence, and reinforcing effect of that initial contact were assessed.

\section{Method}

The subjects were 32 naive female rats, Sherman strain, 3 to 4 months old. They were maintained throughout on Wayne Lab Blox $(<0.25 \% \mathrm{NaCl})$ and tap water. 20 animals were bilaterally adrenalectomized under ether anesthesia, care being taken to remove all of the fat and connective tissues attached to the adrenal capsule (Richter, 1941). The criterion of success of the operation was death between 1 and 3 weeks. Three Ss were discarded because of unsuccessful operations, and a fourth was discarded because of an irregularity in the test procedure. The 16 experimental Ss were divided into two groups and tested 2 days after the operation, one group with a salty wet mash and the other with a plain wet mash (50 cc water, $50 \mathrm{gm}$ ground Wayne Lab Blox, and either with or without $5 \mathrm{gm} \mathrm{NaCl}$ ). 12 unoperated control Ss were run, again, half with the salty mash and half with plain mash.

The test situation was a plain box of approximately cubic shape of $1200 \mathrm{cu}$ in with a glass front wall. A small round food dish containing the test food was located at the front center of the test box. All Ss were food deprived for $24 \mathrm{hrs}$. prior to testing. The test itself consisted of two trials with a 5 min. inter-trial interval. On both trials $\mathrm{S}$ was taken from its home cage and placed in the test box. Under these conditions eating is ordinarily delayed for about $3 \mathrm{~min}$. while the rat explores the novel test environment (Bolles, 1962), although a number of momentary contacts may be made during this latent period. The latency to eat was scored from the time $\mathrm{S}$ was placed in the box until a criterion of $10 \mathrm{sec}$. of continuous eating had been met. $S$ was permitted $50 \mathrm{sec}$. of additional time to eat and then removed from the test box. Any $\mathrm{S}$ failing to eat within 10 min. was scored as giving a $10 \mathrm{~min}$. latency and the trial was terminated.

\section{Results}

The median latencies to eat for the operated and control Ss for both kinds of test foods on both trials are shown in Fig. 1. There were no systematic differences in the latency of the initial contacts with food under the different conditions except for the unoperated control Ss tested with salty food which were significantly slower to 


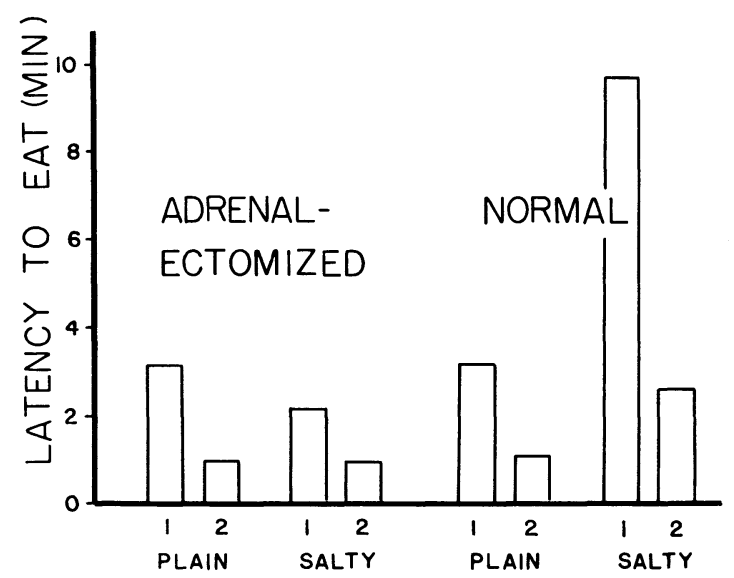

Fig. 1. The latency of hungry adrenalectomized and normal rats to eat plain and salty food on their first two encounters with food in a novel situation.

meet the $10 \mathrm{sec}$. criterion of continuous eating. ${ }^{2}$ Indeed, all 4 of the Ss for which the $10 \mathrm{~min}$. cut off criterion had to be invoked were in this group. It is clear then that the controls showed an immediate aversion to the salty food but that the adrenalectomized Ss did not. In fact, the operated Ss showed a tendency to shorter latencies to eat the salty food, but this tendency was not significant. The same lack of persistence which prevented the controls from meeting the consummatory criterion with salty food is reflected in the small proportion of the total $60 \mathrm{sec}$. of possible consummatory time spent eating (18 sec.) compared with the other 3 groups ( $46 \mathrm{sec}$.). The other 3 groups did not differ significantly on this measure.

The two-trial test procedure was used to test the possibility that the salty food would provide greater reinforcement of eating for the experimental Ss than was provided under any other

\footnotetext{
2.05 level with a Mann-Whitney test. Preliminary investigation with $\mathrm{Ss}$ tested $1,3,5$ and 9 days postoperatively had indicated no systematic variation in the latency to eat; the duration of the adrenal insufficiency does not seem to be critical for our results.
}

combination of conditions. The relative drop in latency between the first and second trials can be taken as a measure of reinforcement. As can be seen from Fig. 1, the reinforcing effect of whatever consummatory activity occurred on the first trial produced what were approximately proportional reductions in the latency to eat on the second trial; the ratio of latencies on the two trials did not vary systematically as a function of the testing conditions. This is not to say that there was no learning by the experimental Ss that can be attributed to the beneficial affect of salty food, but only that a comparable amount of learning was displayed by Ss under all conditions, even by the controls with salty food. While we cannot say that there would not have been learning on the basis of a salt need, particularly if more time had been allowed, we can say that there seems to be a palatability or taste factor which occurs prior to any such learning. Control Ss found salty food initially aversive relative to plain food and the adrenalectomized rats did not.

\section{References}

BOLLES, R. C. The readiness to eat and drink: the effect of deprivation conditions. J.comp.physiol. Psychol., 1962, 55, 230-234.

CARR, W. J. The effect of adrenalectomy upon $\mathrm{NaCl}$ taste threshold in the rat. J.comp. physiol. Psychol., 1952, 45, 377-380.

EPSTEIN, A. N., and STELLAR, E. The control of salt preference in the adrenalectomized rat. J. comp. physiol. Psychol., 1955, 48, 167-172.

RICHTER, C. P. Salt taste thresholds of normal and adrenalectomized rats. Endrocrinology, 1939, 24, 367-371.

RICHTER, C. P. The internal environment and behavior. Amer. J. Psychol., 1941, 97, 878-893.

SMITH, M. P., POOL, R., and WEINBERG, H. Evidence for a learning theory of specific hunger. J. comp. physiol. Psychol., 1958, 51, 758-763.

\section{Aeknowledgment}

Supported in part by research grant G-24245 from the National Science Foundation. 